\title{
AN ELECTROPHYSIOLOGICAL INVESTIGATION OF SKELETAL MUSCLES IN POLYMYOSITIS
}

\author{
R. E. P. SICA \\ Olga P. SANZ* \\ Nidia Aguilera
}

A. Colombi

The aim of the present investigation is to report the results of a detailed electrophysiological examination of muscle and motor nerve functions in patients with polymyositis.

The present study has involved mainly the quantification of operative motor units within the extensor digitorum brevis (E.D.B.), thenar and hypothenar muscles.

\section{MATERIAL AND METHODS}

Altogether 25 patients were studied, they were aged 17 to 59 years and, on clinical, laboratory and histopathological grounds, were judged to have polymyositis (Type alpha, World Federation of Neurology Research Group on Neuromuscular Disorders, 1968).

The patients were divided into two groups: the first group of 21 patients comprised those suffering from primary, chronic polymyositis; the remaining 4 patients with acute polymyositis made up a second group. 125 healthy subjects aged 16 to 59 years served as controls for one or more investigations.

The number of motor units in the E.D.B. muscle was estimated by the method of McComas, Fawcett, Campbell and Sica ", while the number of operative motor units within the thenar and hypothenar muscles was obtained by the technique described by Sica, McComas, Upton and Longmire ${ }^{\circ}$.

Measurements were made of impulse conduction velocities and terminal latencles in motor nerve fibres following a convenctional technique.

In all the patients concentric needle electromyography was performed; these studies often served to clarify the diagnosis but the results will not be reported.

Throughout the text mean values have been given with their standard deviations. The significance of difference between means was calculatde by the " $\mathrm{t}$ " test.

Sección de Electroneurofisiologia Clinica, Neurologia, Hospital Ramos Mejla, Buenos Aires, Argentina: * Research fellow, Municipalidad de la Ciudad de Buenos Aires. 


\section{RESULTS}

Numbers of motor units - Table I shows the individual values of operative motor units in each of the muscles investigated in both groups of patients.

In the group of chronic polymyositis of the 20 patients where the E.D.B. muscle was examined low values were observed in 8 , the thenar muscles were investigated in 20 patients too and low values were found in 12 , while of 19 patients who were submitted for hypothenar muscles investigation 9 showed values below the lower limit of the control group. When the whole group was analyzed the mean values were significantly different from the control means (E.D.B.: patients $148 \pm 76$, controls $215 \pm 69, \mathrm{P}<0.01 ;$ thenar: patients $180 \pm 83$, controls $340 \pm 87, \mathrm{P}<0.001$; hypothenar: patients $267 \pm 106$, controls $379 \pm 79$, $\mathbf{P}<0.001)$.

\begin{tabular}{|c|c|c|c|c|c|c|c|c|c|}
\hline \multirow[t]{2}{*}{ Case } & Length & \multicolumn{2}{|c|}{ E.D.B. } & \multicolumn{2}{|c|}{ Thenar } & \multicolumn{2}{|c|}{ Hypothenar } & \multicolumn{2}{|c|}{$\begin{array}{c}\text { Terminal } \\
\text { latencies (ms) }\end{array}$} \\
\hline & $\begin{array}{l}\text { of history } \\
\text { (months) }\end{array}$ & $n$ & $\begin{array}{c}\bar{x} \\
(u V)\end{array}$ & $n$ & $\begin{array}{c}\bar{x} \\
(u V)\end{array}$ & $\mathrm{n}$ & $\begin{array}{c}\bar{x} \\
(u v)\end{array}$ & d.p. & u. \\
\hline
\end{tabular}

Chronic polymyositis

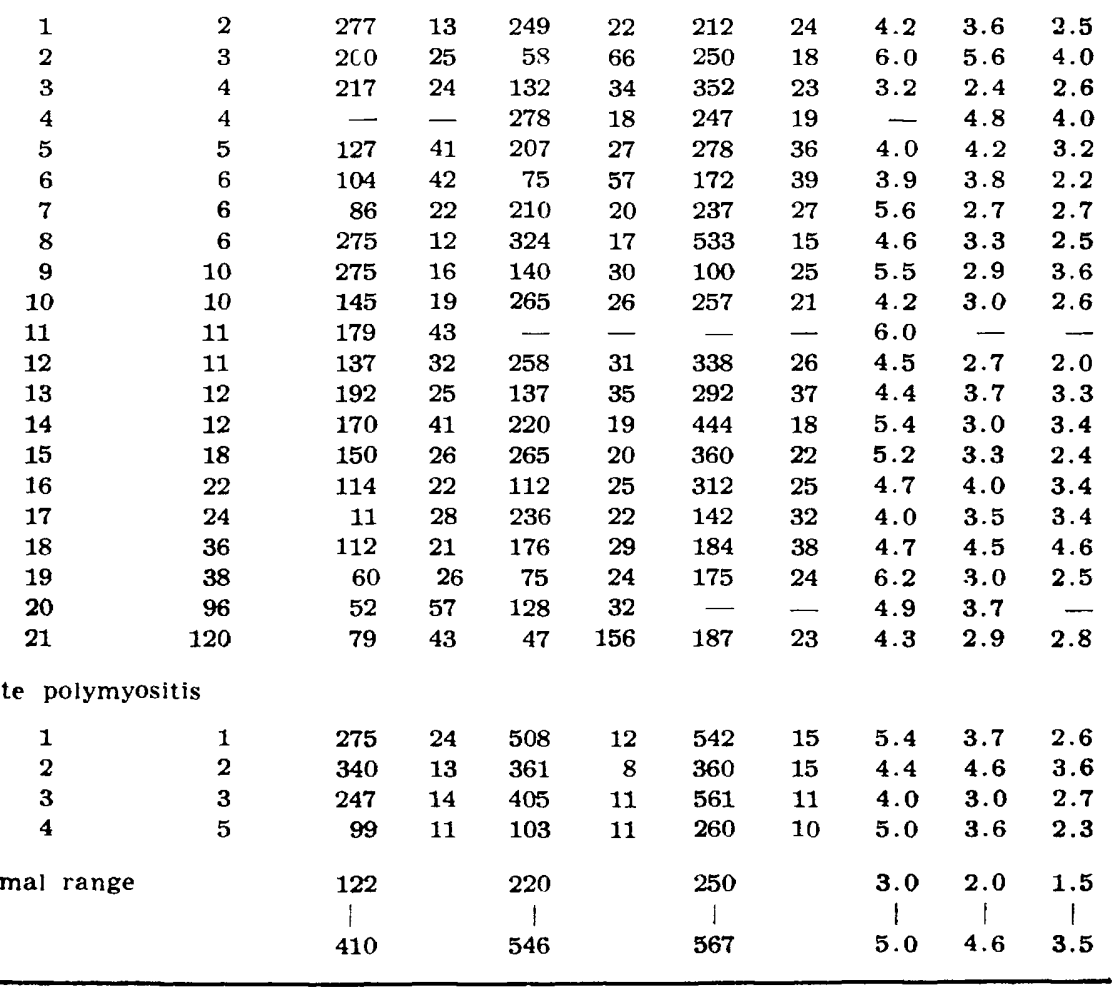

Table 1 - Results in polymyositis: $n=$ number of functioning motor units; $\bar{x}=$ mean size of motor unit potentials amplitude; d.p. = deep peroneal nerve; $m$. = median nerve; u. ulnar nerve. 


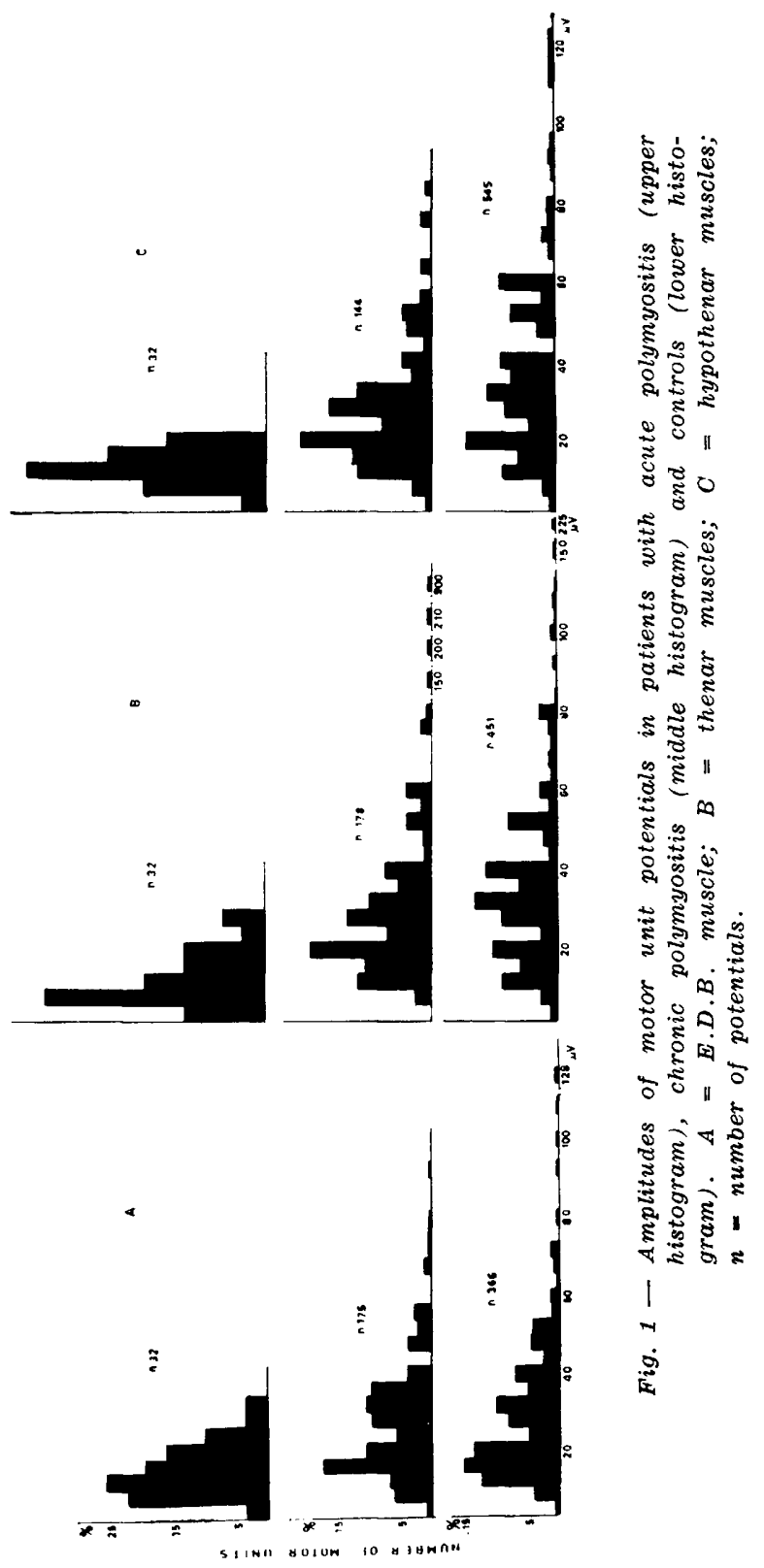


Table 1 shows too that the loss of units was already evident in some muscles shortly after the starting of the disease. However there was a light correlation between the loss of functioning motor units and the length of history, being this behaviour more evident in the E.D.B. muscle and less consistent in the hypothenar muscles $(r$ for E.D.B.: $-0.52, \mathrm{P}<0.02$; for thenar: $-0.39, \mathrm{P}<0.1$; for hypothenar: $-0.38, P>0.1$ ).

In the second group of patients who were affected by acute polymyositis only one of them, who was the one with the longest history of disease, showed a diminished number of motor units in the E.D.B. and thenar muscles.

Sizes of the remaining motor units - In figure 1 the measurements of motor unit potential amplitudes have been pooled for all the patients affected by chronic and acute polymyositis in separated pictures, irrespective of the duration of the disease or the number of surviving units.

It can be seen that the values derived from muscles in patients affected by chronic polymyositis tend to be smaller than the controls despite that the mode in E.D.B. and hypothenar muscles coincides with the normals; in acute polymyositis there is a definite tendency for the results to be smaller.

When the mean sizes of the recruited motor units belonging to each patient affected by chronic polymyositis were compared with the length of history it was found a tendency, in E.D.B. and thenar muscles, to increase progressively their territories ( $r$ for E.D.B.: $0.54, \mathrm{P}<0.02$; for thenar: $0.66, \mathrm{P}<0.01$ ); this behaviour

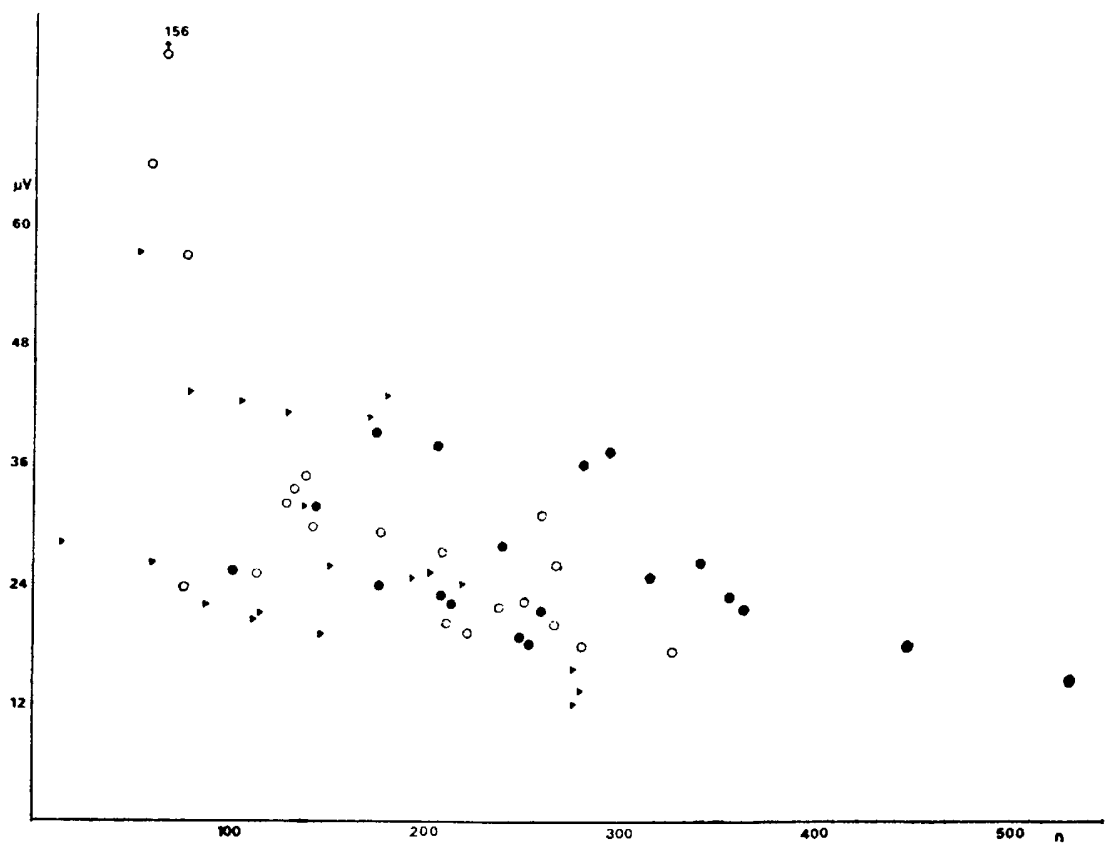

Fig. 2 - Mean amplitude of motor unit potentials in each patient affected by chronic polymyositis as a function of the number of surviving units ( $n$ ): triangles = E.D.B. muscle; open circles $=$ thenar muscles; filled circles = hypothenar muscles. 
was not noted in the hypothenar muscles ( $r$ for hypothenar: 0.10 ). However when the numbers of the remaining units were compared with their mean sizes the three muscles investigated behaved in a similar way $(r$ for E.D.B.: $-0.52, P<0.02 ;$ for thenar: $-0.56, P<0.01$; for hypothenar: $-0.63, P<0.01$ ) showing that the still surviving units try to compensate the loss of operative motor units by increasing their territories (figure 2).

Motor conduction velocities and terminal latencies - In all the patients the maximum conduction velocities of impulses in motor nerve fibres of the deep peroneal, median and ulnar nerves were within the normal range for this laboratory (deep peroneal: 40-60 m/s; median: 50-71 m/s; ulnar: 51-72 m/s).

A comparison was also made of the terminal latencies in the control and 111 populations, this latency being measured as the time elapsing between the stimulation of the most distal point of the nerve (ankle for the deep peroneal and wrist for median and ulnar) and the onset of post-synaptic activity in the concerned muscle. In chronic polymyositis some of the patients showed latencies longer than the control population (table 1); indeed the differences between the normal and patients means were significant for the three nerves investigated (deep peroneal: patients $4.77 \pm 0.80 \mathrm{~ms}$, controls $4.23 \pm 0.57, \mathrm{P}<0.01$; median: patients $3.53 \pm 0.79$ $\mathrm{ms}$, controls $2.95 \pm 0.56, \mathrm{P}<0.01$; ulnar: patients $3.03 \pm 0.68 \mathrm{~ms}$, controls $2.56 \pm$ $0.47, \mathrm{P}<0.01$ ). The same sort of behaviour could be seen in acute polymyositis, but the small samples did not allow a statistical evaluation.

\section{DISCUSSION}

The loss of operative motor units which was noted in chronic polymyositis and also in one of the four patients with acute polymyositis may have different explanations; one of them would be the involvement of the peripheral nervous system in the disease as the main cause, if this would be so, one would expect that, as happens with other forms of dennervation, the remaining healthy units will enlarge their muscle fiber territories ${ }^{8}$. This behaviour was noted in chronic polymyositis when the correlation between number of surviving units and their mean sizes was analyzed, in thenar and E.D.B. muscles that enlargement was lightly related with the lengtn of history. However looking at figure 1 it can be seen that the sizes of the remaining units are within the distribution of the control population tending to bunch up on the left side of the picture. This behaviour is quite different to the one which can be expected if healthy, undamaged units would take over the muscle fibers relinquished by its original innervation. Therefore the explanation which can be given so far is that the disease affects at the same time the muscle fibers and their motor innervation.

This combination could make that an individual motor unit loses muscle fibers by a primary involvement of them, this would lead to a diminished size motor unit population and eventually, if the loss of muscle fibers becomes severe, whole units would disappear: This sort of behaviour probably plays the main role in acute polymyositis where it has been noted that the remaining population of motor units had a definite diminished size regarding the control units. However this simple interpretation cannot fully be applied to chronic polymyositis where a large proportion of the remaining units had 
sizes similar to the normal units; in this last condition the fact that there is an attempt of the remaining units to increase their sizes when the total number of operative units shows a tendency to be reduced suggests that, somehow, the peripheral nervous system is involved.

Bauwens $^{2}$ in 1949 described a syndrome compound by signs of neuropathic and myopathic degeneration believing that it resulted from a lesion of the motor axon distal to its point of branching; Guy, Lefebvre, Lerique and Scherrer ${ }^{5}$ in 1950 demonstrated the same sort of features in dermatomyositis which lately was attributed by Bauwens ${ }^{1}$ to a degeneration of the distal portion of the axonal branches; Coërs and Woolf ${ }^{3}$ in 1959 demonstrated the swelling of subterminal nerve fibres and end-plates as well as the axonal sprouting and collateral reinnervation of muscle fibers in polymyositis, these changes in motor innervation apparently involved the most distal part of the nerve fibres. Recently Engel, Jerusalem, Tsujihata and Gomez ${ }^{4}$ demonstrated the presence of degenerating nerve terminals in polymyositis and morphometric abnormalities consisting in an increased mitochondrial content and decreased synaptic vesicle density in the nerve terminal supporting the assumption that intramuscular nerves may be affected in this disease. These findings lead to the interpretation that in polymyositis there is a combination of primary and secondary involvement of muscle fibers.

In keeping with this concept, in chronic polymyositis a motor unit could be losing muscle fibers by primary involvement of them or by damage of some of its terminal axonal branches and simultaneously acquiring muscle fibers by adopting those which have been denervated by the already mentioned axonal damage. This would result in a sort of equilibrium where a motor unit could mantain a size similar to the controls. Of course, one cannot reject the possibility that in acute polymyositis the motor innervation would have been damaged as well as in chronic polymyositis, but probably the severe muscle involvement which occurs in this condition maskes any electrophysiological manifestation of the peripheral nervous system participation with the technical approach employed in the present study, except the prolonged terminal latencies in motor fibres.

The above reasons lead to the conclusion that in polymyositis whole motor units can be lost by two individual mechanisms or, more probably, a combination of both; the first one would be a primary muscle involvement which might "kill" individual muscle fibers up to the disappearance of the whole unit and the second would be the axonal degeneration.

The axonal damage can explain too the prolonged terminal latencies seen in these patients, not only by the damage itself but by the branches sprouted from an undamaged axon which have diminished conduction velocity ${ }^{6}$.

\section{SUMMARY}

An electrophysiological study has been made of the extensor digitorum brevis, thenar and hypothenar muscles in 25 patients with chronic and acute 
polymyositis. It was found a reduction of the number of functioning motor units in some patients with chronic polymyositis and only in one of those affected by acute polymyositis. The sizes of the surviving units suggested that the results could be explained in terms of a primary muscle involvement mainly in acute polymyositis, while in chronic polymyositis a combination of primary and neurogenic involvement of muscle fibers might take place.

\section{RESUMO}

\section{Investigação eletrofisiológica de músculos esqueléticos na polimíosite}

Foi feito estudo eletromiográfico do curto extensor dos dedos e dos músculos tenares e hipotenares em 25 pacientes com polimíosite crônica e aguda. Foi encontrada diminuição no número de unidades motoras funcionantes em alguns pacientes com polimiosite crônica e somente em um caso de polimíosite aguda. Os tamanhos das unidades restantes sugerem que os resultados podem ser explicados em termos de um envolvimento primário dos músculos especialmente na polimiosite aguda, ao passo que na polimiosite crônica ocorre uma combinação de acometimento primário e neurogênico.

\section{REFERENCES}

1. BAUWENS, P. - Electrodiagnosis in motor unit dysfunction. Proc. R. Soc. Med. 48:194, 1955 .

2. BAUWENS, P. 1949 - Quoted by COERS \& WOOLF, 1959.

3. COERS, C. \& WOOLF, A.L. - The innervation of muscle: a biopsy study. Blackwell Scientific Publications, Oxford, 1959. pp. 118-124 and 133-134.

4. ENGEL, A.G.; JERUSALEM, F.; TSUJIHATA, M. \& GOMEZ, M.R. - The neuromuscular junction in myopathies. A quantitative ultrastructural study. In "Recent Advances in Myology". Ed. W. Bradley, D. Gardner-Medwin \& J.N. Walton. Amsterdam, 1975. pp. 132-143.

5. GUY, E.; LEFEBVRE, J.; LERIQUE, J. \& SCHERRER, J. - Les signes electromyographiques des dermatomyositis. Rev. Neurol. (Paris) 83:278, 1950.

6. LUDIN, H.P. - Pathophysiologische Grundlagen Elektromyographischer Befunde bei Neuropathien und Myopathien. Georg Thieme Verlarg, Stuttgart, 1975. pp. 61-62.

7. MCCOMAS, A.J.; FAWCETT, P.; CAMPBELL, M.J. \& SICA, R.E.P. - Electrophysiological estimation of the number of motor units within a human muscle. J. Neurol, Neurosurg. Psychiat. 34:121, 1971.

8. McCOMAS, A.J.; SICA, R.E.P.; CAMPBELL, M.J. \& UPTON, A.R.M. Functional compensation in partially denervated muscles. J. Neurol. Neurosurg. Psychiat. $34: 433,1971$.

9. SICA, R.E.P.; MCCOMAS, A.J.; UPTON, A.R.M. \& LONGMIRE, D. - Motor unit estimations in small muscles of the hand. J. Neurol. Neurosurg. Psychiat. $37: 55,1974$.

Sección de Electroneurofisiología - Hospital Ramos Mejía - Urquiza 609 Buenos Aires - Argentina. 